\title{
Self-Reported and Objectively Measured Physical Activity of Elderly Men from the Canton Sarajevo
}

\author{
Izet Bajramovic $^{1}$, Denis Causevic ${ }^{1}$, Damira Vranesic-Hadzimehmedovic ${ }^{1}$, Amel Mekic ${ }^{1}$, Marijana \\ Podrug-Arapovic ${ }^{1}$, Slavenko Likic ${ }^{1}$ \\ ${ }^{1}$ University of Sarajevo, Faculty for Sport and Physical Education, Sarajevo, Bosnia and Herzegovina
}

\begin{abstract}
The aim of this study was to determine the level of physical activity of elderly men living in the Canton of Sarajevo in Bosnia and Herzegovina. The sample consisted of 162 subjects, divided in two sub-sample: first group aged 50-59 $(55.17 \pm 2.91), \mathrm{N}=84$; and second group aged $60-69(65.01 \pm 3.04), \mathrm{N}=78$. Data collection was obtained using a long version of the International Physical Activity Questionnaires (IPAQ). After the analysis of the results, a high overall level of physical activity of the treated sample of elderly men was determined. The first group of elderly men (age 50-59) achieved the total work MET 18234.33 \pm 40827.53 ; the second group of elderly men (age 60-69) achieved the total work MET $14324.09 \pm 31249.24$. Determined exceptionally heavy physical activity (MET) was the most dominant mode of energy consumption in the case of both elderly groups, was not expected. Statistical significance was observed in the variables of total activity in transport $(p<0.05)$. No statistically significant differences were found in all other variables ( $p>0.05)$. This research has confirmed that physical activity decreases with age. Promoting physical activity to improve the quality of life of elderly people should be a priority task of health policy of all local communities. It is important to provide appropriate ways of information about the health status of elderly persons in order to determine priorities, and accordingly plan appropriate programs of physical activity.
\end{abstract}

Key words: Metabolic Equivalent of MET, Older Age, Health, Local Community

\section{Uvod}

Poznato je da starenje za posljedicu ima opadanje tjelesnih sposobnosti čovjeka, što je uz globalni problem hipokinezije, jedan od vodećih savremenih problema društva (Čaušević, Ormanović, Doder, \& Čović, 2017; Ćirić, Čaušević, \& Bejdić, 2015). Individualni aerobni fitness se smanjuje za $8-10 \%$ tokom svake decenije života, dok veoma aktivni ljudi mogu smanjiti ovaj nivo na $2-3 \%$. Opadanje snage je osjetno u šezdesetim, a posebno u sedamdesetim godinama života (15\% odnosno 30\%), (Sharkey \& Gaskill, 2008). Takođe u brojnim studijama, utvrđeno je da su promjene koje nastaju kao posljedica biološkog starenja, povezane sa smanjenim stepenom fizičke aktivnosti osoba starije dobi, a koje za posljedicu imaju smanjenje mišićne mase i tjelesne funkcije.

Poznato je da organizovano tjelesno vježbanje ima mnogo pozitivnih efekata na organizam čovjeka u cjelini, te da ima jasan i prioritetan fizički i zdravstveni uticaj na osobe i njihove radne aktivnosti. Međutim, bez obzira na to šta osoba radi - bilo da se bavi prostim fizičkim poslom (nošenjem, podizanjem, poljoprivrednim radom) ili vrši fizičke vježbe, njen mišićni, kardio-vaskularni, respiratorni i centralni nervni sistem aktivno funkcionišu. Shodno tome će fizička aktivnost, bilo kao tjelesna vježba ili fizički rad, uvijek uticati na naše tijelo i tako dovesti do povećanog nivoa funkcionisanja (Bjelica \& Krivikapić, 2019).

S druge strane, neaktivnost uzrokuje $9 \%$ prerane smrtnosti, što brojem iznosi više nego 5,3 od 57 miliona smrtnih slučajeva širom svijeta tokom 2008. godine (Lee i sar. 2012). Istoimeni autori navode da ukoliko neaktivnost nije eliminisana ali jeste umanjena za $10 \%$ ili $25 \%$, onda bi se smrtnost tokom svake godine mogla izbjeći za više od 533000 odnosno za više od 1,3 miliona slučajeva. Ovakav navod potvrđuje i činjenica da

\section{Montenegro}

Sport

\section{Correspondence:}

S. Likic

University of Sarajevo, Faculty for Sport and Physical Education, Patriotske lige 41, 71000 Sarajevo, Bosnia and Herzegovina

E-mail: slavenkolikic@gmail.com 
je svaka osoba bez obzira na starost u mogućnosti da izvodi neki tip prilagođene tjelesne aktivnosti (Močnik, Neuberg, \& Canjuga, 2015).

Nivo tjelesne aktivnosti je prvobitno potrebno procijeniti. U skladu s tim, Jurakić \& Andrijašević (2008) navode da je glavni cilj metoda mjerenja tjelesne aktivnosti procjena energetske potrošnje. Obzirom da je energetska potrošnja rezultat različitih tjelesnih aktivnosti, metode procjene se uslovno mogu podijeliti na tri osnovne grupacije: laboratorijske metode kao najpreciznije (kalorimetrija - pogreška manja od $1 \%)$, metode zasnovane na korištenju elektronskih sprava $\mathrm{i}$ instrumenata (pedometri, akcelometri i monitori srčane frekvencije), te anketne metode zasnovane na samoprocjeni tjelesne aktivnosti ispitanika (globalni upitnici, kratki upitnici prisjećanja i detaljni upitnici tjelesne aktivnosti).
Cilj ovog istraživanja je utvrđivanje nivoa fizičke aktivnosti starijih muškaraca od 50-59 i 60-69 godina starosti, te promocije zdravog stila života u lokalnoj zajednici.

\section{Metod}

Uzorak ispitanika su činile osoba muškog pola $(\mathrm{N}=162)$, nastanjene u Kantonu Sarajevo, Bosna i Hercegovina. Prema hronološkoj starosti uzorak ispitanika je klasifikovan na dva subuzorka: prvi subuzorak $(\mathrm{N}=84$; starosna dob: $55.17 \pm 2.91)$ u kojem je $85,7 \%$ ispitanika nastanjeno u gradskom području, a $14,3 \%$ ispitanika je naseljeno u ostalim naseljima izvan grada; te drugi subuzorak $(\mathrm{N}=78$; starosna dob: $65.01 \pm 3.04)$ u kojem je 82,8\% nastanjeno u gradskom području, a 17,2\% ispitanika je nastanjen izvan grada (Tabela 1). Svi ispitanici su dobrovoljno pristupili istraživanju.

Tabela 1. Osnovne karakteristike uzorka ispitanika

\begin{tabular}{ccc}
\hline Starosna dob (N) & AS \pm SD & $\%$ \\
\hline $50-59$ & $55,17 \pm 2,91$ & 51,85 \\
$60-69$ & $65,01 \pm 3,04$ & 49,15 \\
\hline
\end{tabular}

Legenda: AS - aritmetička sredina; SD - standardna devijacija.

Za potrebe ove studije koristila se duga verzija međunarodnog anketnog upitnika (IPAQ - International Physical Activity Questionnaires), koja obuhvaća četiri domene samoprocjene fizičke aktivnosti: fizička aktivnost na poslu; fizička aktivnost u prevozu; kućni poslovi, održavanje kuće i briga za porodicu; i rekreacija, sport i fizička aktivnost u slobodno vrijeme (Craig i sar., 2003). Fizičke aktivnosti se tretiraju kao teška, umjerena i niska (hodanje/šetanje). Rezultati su izraženi pomoću metaboličkog ekvivalenta (MET -
Metabolic Equivalent of Task) koji je izražen u min/nedjelja. Anketiranje je sprovedeno u mjesecu oktobru i novembru, 2017. godine. Zbog neodgovarajuće godine rođenja, mjesta stanovanja izvan područja Kantona Sarajevo ili nepotpuno popunjenog obrasca, iz konačne obrade rezultata je isključeno ukupno devet anketnih upitnika. Da bi se odredio nivo energetske potrošnje prilikom fizičkih aktivnosti, prema preporuci autora Ainsworth i sar. (2000), korištene su formule prikazane u Tabeli 2 .

Tabela 2. Predložene IPAQ vrijednosti i računske formule

\begin{tabular}{cc}
\hline Fizička aktivnost & Formula \\
\hline Hodanje $=3.3$ MET & $3.3 *$ vrijeme FA u minutama * broj dana u nedjelji \\
Umjerena FA $=4.0$ MET & $4.0 *$ vrijeme FA u minutama * broj dana u nedjelji \\
Teška FA $=8,0$ MET & $8.0 *$ vrijeme FA u minutama * broj dana u nedjelji \\
Ukupna FA MET-min u nedjelji & Hodanje + umjerena FA + teška FA \\
\hline
\end{tabular}

Legenda: MET - metabolički ekvivalent; FA - fizička aktivnost.

Podaci su obrađeni korištenjem statističkog paketa SPSS 23. za operativni sistem Windows (SPSS Inc., Chicago, IL, USA). Kao primarno, izračunate su aritmetička sredina (AS) i standardna devijacija (SD), dok je statistička značajnost razlika između dvije grupe utvrđena primjenom t-testa za nezavisne uzorke, na postavljenom nivou statističke značajnosti od $\mathrm{p}=0.05$.

\section{Rezultati}

Na temelju uvida u osnovne deskriptivne parametre (Tabela 3), uočavaju se veće prosječne vrijednosti grupe muškaraca 50-59, u odnosu na grupu 60-69 godina starosti.

Tabela 3. Fizička aktivnost tretiranih grupa muškaraca starije dobi sa područja Kantona Sarajevo u proteklih sedam dana

\begin{tabular}{ccccc}
\hline Domena fizičke aktivnosti & $\begin{array}{c}\mathbf{5 0 - 5 9} \\
\mathbf{( N = 8 4 )}\end{array}$ & $\begin{array}{c}\mathbf{6 0 - 6 9} \\
\mathbf{( N = 7 8 )}\end{array}$ & \% & $\begin{array}{c}\text { Sig. } \\
\text { (2-tailed) }\end{array}$ \\
\hline Ukupne aktivnosti na poslu (MET) & $7619.64 \pm 25813.18$ & $6932.44 \pm 21169.65$ & 9.02 & .854 \\
Ukupne aktivnosti u prevozu (MET) & $5374.40 \pm 6353.57$ & $3006.15 \pm 3502.23$ & 44.07 & .004 \\
Ukupne aktivnosti u dvorištu i kući (MET) & $3456.83 \pm 4845.93$ & $2590.67 \pm 4292.36$ & 25.06 & .232 \\
Ukupne aktivnosti u slobodnom vremenu (MET) & $1783.53 \pm 3814.85$ & $1794.83 \pm 2285.00$ & -0.63 & .982 \\
Ukupno hodanje (MET) & $5495.67 \pm 9560.35$ & $3555.53 \pm 3870.50$ & 35.30 & .448 \\
Ukupne aktivnosti umjerenog inteziteta (MET) & $3561.42 \pm 3784.00$ & $2986.66 \pm 4810.58$ & 16.14 & .097 \\
Ukupne izrazito naporne aktivnosti (MET) & $7012.38 \pm 8927.98$ & $5981.21 \pm 8275.50$ & 14.70 & .089 \\
Ukupan rad (MET) & $18234.33 \pm 40827.53$ & $14324.09 \pm 31249.24$ & 21.44 & .318 \\
\hline
\end{tabular}


Razlika je posebno izražena u varijabli ukupnih aktivnosti u prevozu, koja iznosi 2368.25 MET (44.07\%) u korist mlađe starosne grupe, odnosno u varijabli ukupan rad, gdje je prisutna razlika od 3910.35 MET (21.44\%), takođe u korist mlađe starosne grupe. Generalno je primijetno da se razina potrošnje energije smanjuje sa procesom starenja kod starijih muškaraca od 9,02\% do 44,07\%. Ipak, statistička značajnost između dvije grupe je uočena jedino u varijabli ukupne aktivnosti u prevozu $(\mathrm{p}<0.05)$. U ostalih sedam varijabli nije uočena statistička značajnost $(\mathrm{p}>0.05)$.

\section{Diskusija}

Generalno posmatrajući dobijene rezultate, ustanovljene su vrlo visoke prosječne vrijednosti ukupne energetske potrošnje (MET) u odnosu na nalaze studije Kyu i sar. (2016), gdje su navedene sljedeće vrijednosti: slabije aktivni (600-3999 MET minuta), umjereno aktivni (4000-7999 MET minuta) i visoko aktivni ( $\geq 8000$ MET minuta). Prema ovim autorima, više vrijednosti su usko povezane sa smanjenim rizikom od različitih bolesti vezanih za rak, dijabetes i ishemijske bolesti srca.

U poređenju sa rezultatima prethodnih studija (Bajramović, Bjelica, Talovic, Alic, \& Likic, 2018), može se konstatovati da su muškarci starije dobi nastanjeni u Kantonu Sarajevo fizički aktivniji u odnosu na žene nastanjene u istom kantonu, odnosno da su fizički aktivniji za 23,3\% u slučaju starosne grupe 50-59 godina, te fizički aktivniji za $30,7 \%$ u slučaju starosne grupe 60-69 godina. Valja naglasiti da su žene sa područja Kantona Sarajevo za 25,4\% fizički aktivnije u slobodno vrijeme u odnosu na muškarce u slučaju starosne grupe ispitanika 50-59 godina, odnosno $16,6 \%$ u slučaju starosne grupe 60-69 godina. Takođe, interesantan je podatak, da je energetska potrošnja prilikom poređenja starosnih grupa muškaraca i žena u slučaju ukupnih izrazito napornih aktivnosti bila dosta približna. Upoređivanjem rezultata ove studije sa rezultatima studija koje su realizirane sa identičnim pristupom testiranju, na uzorcima starijih muških osoba nastanjenih na području crnogorskih gradova - Bar i okolina (Kovacevic, 2018) i Nikšić i okolina (Mitrovic, 2018), može se konstatovati da su muškarci sa područja Kantona Sarajevo prijavili nešto veći nivo fizičkih aktivnosti u proteklih sedam dana od dana ispitivanja.

$\mathrm{Na}$ relativno visoku prevalenciju fizičke neaktivnosti u slučaju žena, odnosno muškaraca starije dobi, a koja se povećava u skladu sa starosnom dobi, ukazuju novija istraživanja (Popovic, Bjelica, Vukotic, \& Masanovic, 2018; Masanovic, Vukotic, Bjelica, \& Popovic, 2018). Fizička aktivnost tokom starije životne dobi je vrlo važna, obzirom da starost kao i sama neaktivnost uzrokuju promjene, koje se u pravilu mogu smanjiti i držati pod kontrolom samo redovnom fizičkom aktivnošću (Močnik i sar., 2015). Svaki oblik pokreta tijela koji povećava energetsku potrošnju smatra se fizičkom aktivnošću. Za zdravlje čovjeka veoma je bitno odrediti adekvatne fizičke aktivnosti kako bi iste na najbolji način uticale na naš organizam (Bjelica, 2015).

S druge strane, fizička neaktivnost ima veliki uticaj na zdravlje ljudi širom svijeta, te bi se umanjenjem ili uklanjanjem ovakvog nezdravog ponašanja zdravlje moglo značajno globalno poboljšati (Lee i sar. 2012). Primarni i prirodni odgovor na ovakve tvrdnje nalazi se u kineziološkoj rekreaciji, odnosno fizičkoj aktivnosti koja se praktikuje u slobodno vrijeme (Papec, 2016). Takođe, kada je u pitanju korišćenje slobodnog vremena, isto pomaže starijim ljudima da poboljšaju svoje socijalne odnose upoznavajući se jedni sa drugima, što u konačnici utiče na nivo zdravlja (Popović \& Bjelica, 2017). Jakicic, Marcus, Gallagher, Napolitano, \& Lang (2003) naglašavaju da fizička aktivnost treba u početku biti usmjerena na usvajanje i održavanje aktivnosti u trajanju od najmanje 150 minuta nedjeljno, te da je kasnije treba povećavati do nivoa od 60 minuta svakodnevne fizičke aktivnosti. Silva Garcez i sar. (2015), ukazuju na važnost doprinosa u informisanju i motivisanju zaposlenih osoba da povećaju svoju fizičku aktivnost i smanje svoj nivo sedentarnog ponašanja, uzevši u obzir karakteristike posla i polne razlike. Pored osoba koje su educirane za zdrave preventivne fizičke aktivnosti, takođe i zdravstveni radnici imaju važnu ulogu u pojedinačnim razgovorima i davanju preporuka u vezi sa zdravim fizičkim aktivnostima (Taylor, 2014).

Može se zaključiti da su muške osobe starije dobi nastanjene na području Kantona Sarajevo pokazale u prosjeku zadovoljavajući nivo energetske potrošnje, ukoliko su uzete u obzir četiri predložene domene fizičke aktivnosti. Ohrabruje činjenica da su u okviru ankete provedene u ovom istraživanju evidentirane relativno visoke vrijednosti energetske potrošnje prilikom napornih aktivnosti.

Opšte je poznato da za svaki pokret u životu postoji potreba za snagom. U skladu s tim može se reći da mišićna snaga omogućava životnu samostalnost ljudi, što je posebno važno za osobe starije dobi. Ovim istraživanjem utvrđeno je da se razina potrošnje energije smanjuje sa procesom starenja kod starijih muškaraca, što je prema rezultatima IPAQ upitnika od $9,02 \%$ do $44,07 \%$. Kao zaključak se također može sugerisati da bi promocija fizičkih aktivnosti radi poboljšanja kvaliteta života starijih osoba trebala biti prioritetni zadatak svih lokalnih društvenih zajednica. U skladu s tim važno je osigurati odgovarajuće načine informisanja o zdravstvenom statusu starijih osoba kako bi se utvrdili prioriteti i planirali odgovarajući programi fizičke aktivnosti.

\section{Acknowledgements}

There are no acknowledgements.

\section{Conflict of Interest}

The authors declare that there are no conflicts of interest.

Received: 28 May 2019| Accepted: 3 June 2019| Published: 4 July 2019

\section{References}

Ainsworth B.E, Haskell, W.L., Whitt, M.C., Irwin, M.L, Swartz, A.M., Strath, S.J., O'Brien WL, Bassett, D.R., Schmitz, K.H., Emplaincourt, P.O., Jacobs, D.R \& Leon, A.S. (2000). Compendium of physical activities: an update of activity codes and MET intensities. Med Sci Sport Exerc., 32(9), 498-504.

Bajramovic, I., Bjelica, D., Talovic, M., Alic, H., \& Likic, S. (2018). Evaluation of the Physical Activity Level of Elderly Women in the Canton of Sarajevo in Bosnia and Herzegovina. J. Anthr. Sport Phys. Educ. 2(4), 33-36.

Bjelica, D., \& Krivikapić, D. (2019). Teorija tjelesnog vježbanja i sporta. Podgorica: Crnogorska sportska akademija.

Bjelica, D. (2015). Teorijske osnove tjelesnog i zdravstvenog obrazovanja (drugo izdanje). Podgorica - Nikšić: Fakultet za sport i fizičko vaspitanje UCG i Crnogorska sportska akademija.

Craig C.L., Marshall A.L., Sjöström M., Bauman A.E., Booth M.L., Ainsworth B.E., Pratt M., Ekelund U., Yngve A., Sallis J.F., \& Oja, P. (2003). International physical activity questionnaire: 12 -country reliability and validity. Medicine and Science in Sports and Exercise, 35(8), 1381-1395.

Čaušević, D., Ormanović, Š., Doder, I., \& Čović, N. (2017). Analysis of Dietary Supplements Usage Among Recreational Athletes In Canton Sarajevo. Homo Sporticus, 19(2), 19-23.

Ćirić, A., Čaušević, D., \& Bejdić, A. (2015). Differences in posture status between boys and girls 6 to 9 years of age. Homo Sporticus, 17(1), 15-20.

Jakicic, JM., Marcus, BH., Gallagher, Kl., Napolitano, M., \& Lang, W. (2003). Effect of exercise duration and intensity on weight loss in overweight, sedentary women: a randomized trial. JAMA, 290(10), 1323-1330. 
Jurakić, D. \& Andrijašević, M. (2008). Mjerenje tjelesne aktivnosti kao sastavnica izrade strategija za unapređenje zdravlja. U Zborniku radova 17. ljetne škole kineziologa Republike Hrvatske. Poreč: Hrvatski kineziološki savez.

Kyu, H.H., Bachman, V.F., Alexander, L.T., Mumford, J.E., Afshin, A., Estep, K, Veerman, J.L., Delwiche, K., lannarone, M.L., Moyer, M.L., Cercy, K., Vos, T., \& Murray, C.J., Forouzanfar, M.H. (2016). Physical activity and risk of breast cancer colon cancer, diabetes, ischemic heart disease, and ischemic stroke events: systematic review and dose-response meta-analysis for the Global Burden of Disease Study 2013. British Medical Journal, i3857. doi: 10.1136/bmj.i3857

Kovacevic, M. (2018). Self-Reported and Objectively Measured Physical Activity of Elderly Mans from Bar. J. Anthr. Sport Phys. Educ., 2(3), 79-83

Lee, IM., Shiroma, EJ., Lobelo, F., Puska, P., Blair, SN., \& Katzmarzyk, PT. (2012). Effect of physical inactivity on major non-communicable diseases worldwide: an analysis of burden of disease and life expectancy. Lancet. 21,380(9838), 219-229. doi: 10.1016/S0140 6736(12)61031-9.

Masanovic, B., Vukotic, M., Bjelica, D., \& Popovic, S. (2018). Describing Physical Activity Profile of Older Montenegrin Males Using the International Physical Activity Questionnaire (IPAQ). In Book of Abstracts of the 15th International Scientific Conference on Transformation Process in Sport "Sport Performance". Podgorica: Montenegrin Sports Academy.

Mitrovic, M. (2018). Self-Reported and Objectively Measured Physical Activity of Males from 50 to 69 Years Old. J. Anthr. Sport Phys. Educ., 2(2), 99-101.
Močnik, A., Neuberg, M., \& Canjuga, I. (2015). Tjelesna aktivnost starijih osoba smještenih u stacionarnim ustanovama. Tehnički glasnik, 9(1), 112-119.

Papec, M., Lovrić, M, \& Papec, M. (2016). Influence of walking on health risk factors with an emphasis on cardiovascular factors. U Zborniku radova 25. ljetne škole kineziologa. Poreč: Hrvatski kineziološki savez.

Popovic, S., Bjelica, D., Vukotic, M., \& Masanovic, B. (2018). Describing Physical Activity Profile of Older Montenegrin Females Using the International Physical Activity Questionnaire (IPAQ). In Book of Abstracts of the 15th International Scientific Conference on Transformation Process in Sport "Sport Performance. Podgorica: Montenegrin Sports Academy.

Popović, S., \& Bjelica, D. (2017). Effcts of physical activity on social exclusionamong older people: a literature review. In Conference Book of Abstract of the 8th Conference of HEPA Europe "Modern Approaches to Physical Activity promotion and measurement"(122). Zagreb: HEPA Europe.

Sharkey, BJ., \& Gaskill, SE. (2008). Vježbanje i zdravlje. Beograd: Data Status.

Garcez, S., Canuto, R., Vieira Paniz, V.M., Olinto, B.A., Macagnan, J Henn, R.L., Pattussi, M.P., \& Anselmo Olinto, M.T. (2015). Association between work shift and the practice of physical activity among workers of a poultry processing plant in Southern Brazil. Nutr Hosp., 31(5), 2174-2181

Taylor, D. (2014). Physical activity is medicine for older adults. Postgrad Med J., $90,26-32$. 